\title{
Perceived Emotional Aptitude of Clinical Laboratory Sciences Students Compared to Students in Other Healthcare Profession Majors
}

\author{
AUSTIN ADAMS, KRISTIN MCCABE, CASSANDRA ZUNDEL, TRAVIS PRICE, COREY DAHL
}

ABSTRACT: Emotional aptitude can be defined as the ability to recognize and manage one's own emotions and interpret the emotions of others. It has been speculated that Clinical Laboratory Sciences students may lack the emotional skills to most effectively interact with patients and other healthcare professionals, therefore a logical hypothesis would be that they would evaluate their own emotional intelligence lower than students from other healthcare majors. While this has been a topic of discussion in healthcare, a lack of research has been conducted to validate this assumption. This study assesses the perceived emotional aptitude of Clinical Laboratory Sciences students compared to students of other healthcare majors in the Dumke College of Health Professions at Weber State University. The perceived emotional aptitude of the healthcare students was determined by completion of a self-evaluation questionnaire that included questions about one's emotions, their understanding of others' emotions, and how they manage conflict. A total of 401 questionnaires were completed, compiled, and analyzed. Although minor differences were seen in the responses, statistical analysis found these differences to be insignificant. The perceived emotional aptitude of Clinical Laboratory Sciences students was insignificantly different than that of students of other healthcare majors at the Dumke College of Health Professions.

Clin Lab Sci 2011;24(3):167

Austin Adams MLS (ASCP), Dumke College of Health Professions. Weber State University, Ogden, UT

Kristin McCabe MLT (ASCP), Dumke College of Health Professions. Weber State University, Ogden, UT
Cassandra Zundel MLS (ASCP), Dumke College of

Health Professions. Weber State University, Ogden, UT

Travis Price MS, MLS (ASCP), Dumke College of Health Professions. Weber State University, Ogden, UT

Corey Dabl MLT (ASCP), Dumke College of Health Professions. Weber State University, Ogden, UT

Address for Correspondence: Travis Price, MS, MLS (ASCP), 3905 University Circle, Ogden, UT 84408, 801-626-8542,Tprice@weber.edu

\section{INTRODUCTION}

Emotional aptitude, also known as Emotional Intelligence (EI) or Emotional Quotient (EQ), refers to the measurement of an individual's ability to understand and manage his/her emotions and interpersonal relationships. ${ }^{1}$ Emotional Intelligence was first notably termed by authors John Mayer and Peter Salovey in 1990, and explored in depth by Daniel Goleman in his 1995 book Emotional Intelligence. In their studies, they found that some people were more capable in identifying their own feelings, identifying the feelings of others, and solving problems involving emotional issues. Since these initial studies, research has been conducted which supports the idea that emotional intelligence may play more of a role in determining success in life than academic ability alone. ${ }^{2}$ Individuals who scored higher on emotional intelligence assessments showed evidence of being better adjusted, more popular, adventurous, confident and dependable later in life. ${ }^{1}$

Studies conducted on social science, science, and business career paths have found that EI may play a direct role in an individual's choice of profession and 


\section{RESEARCH AND REPORTS}

success in that profession. ${ }^{3}$ A similar comparison can be made within healthcare professions as well. Healthcare professions can be divided into two basic groups: those with direct patient contact and those with minimal or indirect patient contact. While formal research in the area is lacking, a logical assumption is often made that those who perceive themselves as more emotionally capable would choose careers that involved more patient interaction, and therefore those who choose careers such as nursing, radiologic sciences and respiratory therapy would have higher levels of perceived emotional intelligence than those who are drawn to professions with less interpersonal interaction, such as laboratory medicine.

Emotional intelligence is often divided into the subgroups of interpersonal communication, self reflection of emotions, and conflict management. ${ }^{4}$ An individual's choice of profession in the healthcare field may be directly related to the strengths and weaknesses that an individual has in these areas of focus, however, clear correlations have not been made with regard to an individual's EI and her or his career selection in the healthcare field.

It was hypothesized that students who selected majors with higher rates of patient interaction would have a higher perceived emotional aptitude than students of majors that have lower rates of patient interaction. Healthcare professions such as nursing, radiologic sciences, respiratory sciences and dental hygiene can involve extensive amounts of interpersonal interaction, whereas clinical laboratory science generally does not. The role of the nurse or respiratory therapist requires a great deal of emotional involvement with patients. They are frequently communicating with doctors and other healthcare professionals about the care of patients. During a regular shift, for example, a nurse may provide care for dozens of patients, each with their own unique emotional and physical needs. Nurses are also responsible for communicating with family members about the condition of patients. In critical care situations or as a patient approaches death a nurse will have intense emotional involvement with that patient and their family. In contrast, a laboratory scientist most often communicates only with other laboratory employees. They communicate with nurses and doctors through brief phone calls about patient results and may never communicate directly with a patient's family. In critical care situations, a laboratory scientist may see only the laboratory result and will have minimal emotional involvement with the patient.

It has been speculated that Clinical Laboratory Science students may lack the emotional skills to most effectively interact with patients and other healthcare professionals, however there is a lack of published research that supports this assumption. Weber State University's Clinical Laboratory Sciences Program is one of the largest in the country with more than 150 active on-campus students and was, therefore, an ideal location for this study. The Dumke College of Health Professions in general graduates more than 1500 students every year with a variety of degrees and certificates in Emergency Care and Rescue, Dental Hygiene, Clinical Laboratory Sciences, Health Administrative Services, Health Information Management, Nursing, Radiologic Sciences, Respiratory Therapy, and General Health Sciences. This study was designed to investigate the difference in perceived emotional aptitude in Clinical Laboratory Sciences students and other majors within the Dr. Ezekial R. Dumke College of Health Professions at Weber State University.

\section{MATERIALS AND METHODS}

The method used for this study was a two-page questionnaire with questions focused on the selfperception of emotions and emotional aptitude. The first page of questions asked participants to answer basic information such as major, age, gender, GPA, and year in school. The second page asked participants to respond to 20 questions pertaining to the three different areas of EI. Questions used in the questionnaire were collected and compiled from various EI sources and were modified for use among health sciences students. The questions were selected based upon three focuses of EI: six questions concerning self-reflection of emotions, seven questions related to emotions during interpersonal communication, and seven questions about managing emotions during conflict. Each question was answered using a Likert scale ranging from one to five, with five being the most favorable emotional response. 


\section{RESEARCH AND REPORTS}

Online questionnaires were performed through SurveyMonkey.com to accommodate participation from online health profession students. A written introduction was provided for the online questionnaires in place of the verbal introductions used for on campus participants.

On campus students completed the online questionnaires during the beginning or end of their scheduled class periods. A verbal introduction was given explaining the content and process to complete the questionnaire. The questionnaire and process for administering it was approved by Weber State University's Institutional Review Board and was given on a voluntary basis and all students were given the opportunity to decline participation.

All questionnaire results were collected and analyzed using Microsoft Excel. This information included major, year in school, GPA, gender, and the chosen numbered response the participant chose for each individual question within the questionnaire. Participants were organized into separate groups based upon their selected major and analysis of the data was performed to establish averages and to analyze the significance of the differences between means.

An Analysis of Variance (ANOVA), calculation was determined to be the most appropriate statistical calculation to determine if the differences seen between groups were significant. The ANOVA also reduces the chances of committing statistical errors that may occur if multiple t-tests were to be performed.

\section{RESULTS}

Four hundred and one questionnaires from seven majors were completed and used for analysis (109 Clinical Laboratory Science, 30 Dental Hygiene, 23 Masters of Nursing, 12 Masters of Health Administration, 152 Nursing, 38 Radiology, and 37 Respiratory Therapy students). Masters of Health Administration and Dental Hygiene students ranked themselves highest in each area with higher overall scores than other healthcare majors. Nursing and Respiratory Therapy students ranked themselves lower than students from other majors in all areas of emotional aptitude assessed by this instrument. Clinical
Laboratory Sciences students were at or above average in all areas except for the section that asked questions related to emotional perceptions during interpersonal communications. In this area CLS students ranked themselves lowest of all the students who participated.

The ANOVA calculation was used with an alpha level of 0.05 . ANOVA results provided an $F$ value of 0.00518 and a critical $F$ of 2.57271 , indicating no statistically significant difference between the scored averages of each major. Additionally, the ANOVA calculation determined that differences between health science majors in overall score or scores as well as in the various categories, such as questions concerning selfreflection of emotions, emotions during interpersonal communication, and those related to managing emotions during conflict were insignificant. Results are summarized in Figures 1-4.

\section{DISCUSSION}

This research was based upon the self-perception of the participant. Self-perception among individuals can be highly subjective and may not always reflect an individual's actual response to emotional situations. All participants in this study were current students, many

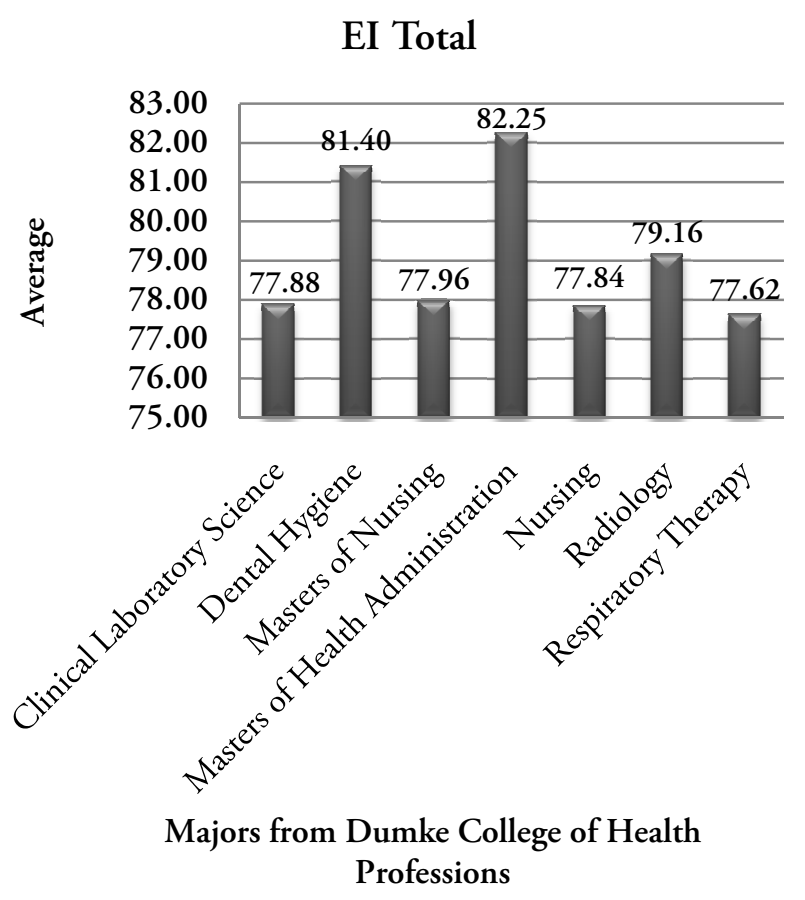

Figure 1. Overall average scores from all healthcare majors. 


\section{Self Reflection Concerning Emotions}

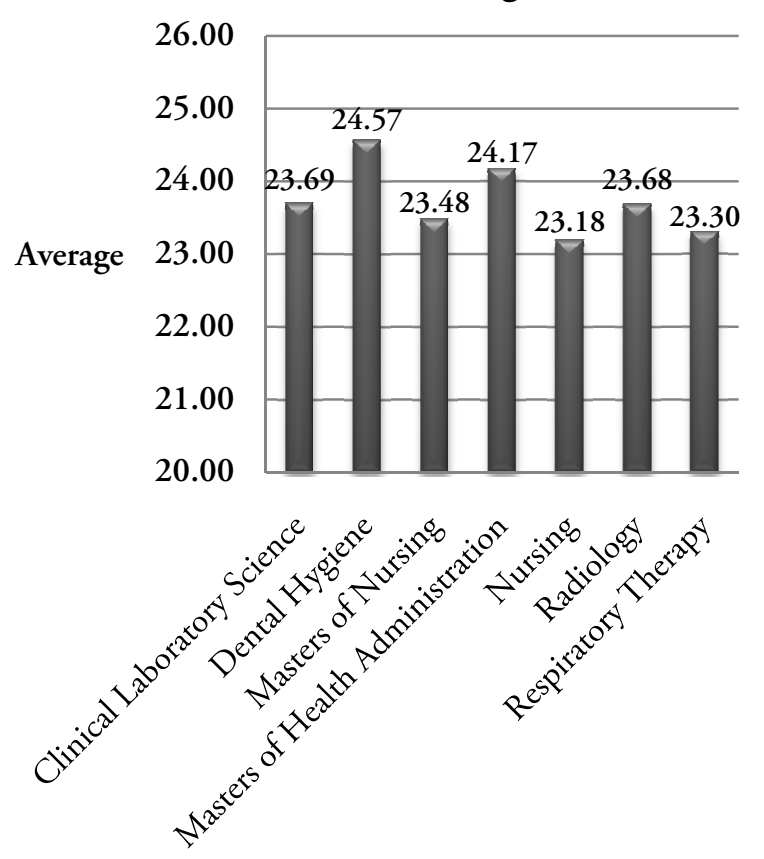

Majors from Dumke College of Health Profession

Figure 2. Average scores for questions concerning self-reflection of emotions

\section{Emotional Perception during Interpersonal Communications}

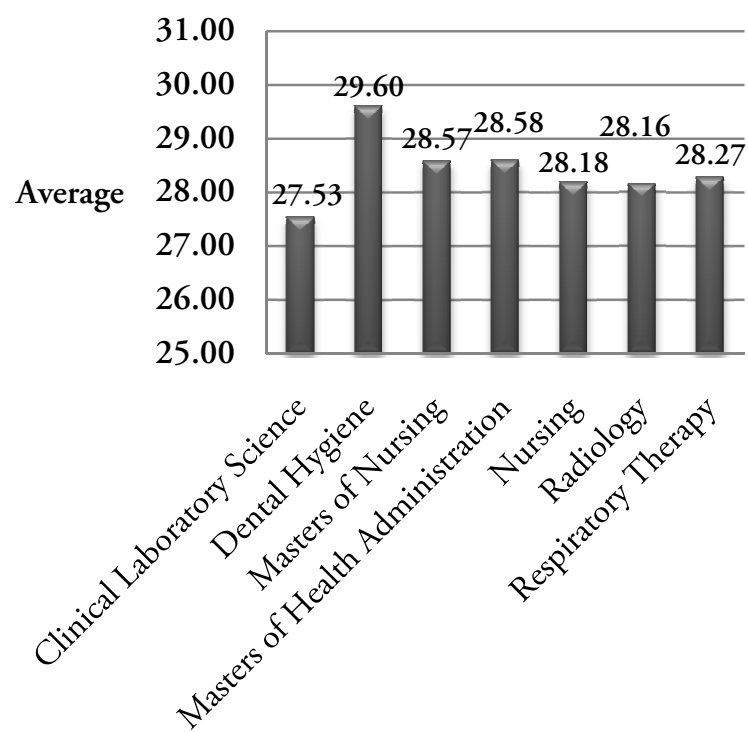

\section{Majors from Dumke College of Health} Professions

Figure 3. Average scores for questions on interpersonal communications

\section{Managing Conflict}

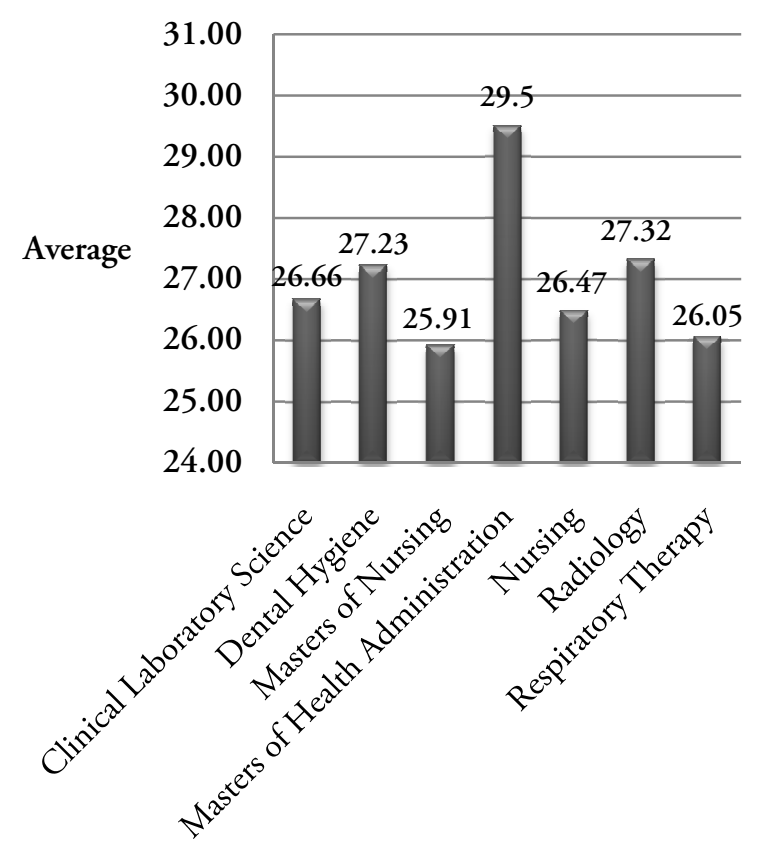

Majors from Dumke College of Health Professions

Figure 4: Average scores for questions on managing conflict

of which may not have had any work experience in their respective field of study. Experience in a specific healthcare field, along with specific situations and scenarios one might encounter in that field, could affect how an individual will perceive herself or himself in emotional situations. The study may have produced different results had it been performed with practicing healthcare professionals. Future studies that focus specifically on practicing healthcare professionals would add significantly to this area of research. Future research on this topic could also benefit from an increased sample size and extending the participant pool beyond Weber State University's Health Sciences Programs.

The initial hypothesis of this study was that there would be a difference in perceived emotional intelligence among health science students, and that this difference would be most apparent between health science fields with little patient contact and those with more patient exposure. The results, however, indicate that any difference in perceived emotional aptitude scores 


\section{RESEARCH AND REPORTS}

between students from the various healthcare majors at Weber State University are statistically insignificant.

One possible explanation is the disparity that exists in the way one perceives their own ability compared to their actual performance of tasks related to that ability. Studies have shown that those who are less capable in a specific area tend to perceive their abilities relatively higher than those who demonstrate higher levels of competency. ${ }^{5}$ In other words, the very deficiencies alluded to in this study's initial hypothesis might explain an overestimation of emotional capacity among laboratory scientists and an underestimation of the same skills among nurses, respiratory therapists and the like.

Another plausible explanation for this difference in perceived emotional aptitude may be the effect of work experience in these healthcare fields. It seems logical to assume that emotional skills will be developed to the extent that they are practiced, and that a person in a healthcare profession with a high degree of patient interaction will more extensively develop these kinds of skills. Likewise, a laboratory scientist with only limited exposure to patients or other healthcare professionals may experience a sort of atrophy in emotional and interpersonal skills. Adherence to standard operating procedures and specific protocols for brief, direct communication may contribute to a decline in emotional and interpersonal skills. It makes sense to assume that the more a laboratory scientist focuses on the technical and analytical skills needed to adequately perform their job, the less likely they are to develop what is often referred to as the softer skills involved with interpersonal communication and emotional interaction.

Regardless of the potential explanations, it is interesting to note the contrast between the way CLS students perceive their emotional aptitude and the way laboratorians are often stereotyped. If these stereotypes are, in fact, based in actual deficiencies in emotional intelligence, it would be beneficial to investigate the nature and the origin of such deficiencies. As the role of the medical laboratory scientist expands, the need for emotional aptitude will also increase. A better understanding of the way emotional and interpersonal skills are developed by health profession students as well as practitioners will be increasingly more important in the years to come.

\section{REFERENCES}

1. Gibbs N. The EQ Factor. Time . 1995, Oct 2

2. Stufft W. Assessing your emotional IQ. Teaching Music, $1996 ; 42$.

3. Kafetsios K, Maridaki-Kassotaki A, Zammuner V, Zampetakis L, Vouzas F. Emotional Intelligence Abilities and Traits in Different Career Paths. Journal of Career Assessment [serial on the internet]. 2009, [cited March 8, 2010],17(4):376-83. Available from: Academic Search Premier.

4. Feldman D. The Handbook of Emotionally Intelligent Leadership: Inspiring Others to Achieve Results. 1999

5. Meyer H. Self-Appraisal of Job Performance. Personnel Psychology. 1980;33(2):291-5

The peer-reviewed Research and Reports Section seeks to publish reports of original research related to the clinical laboratory or one or more subspecialties, as well as information on important clinical laboratory-related topics such as technological, clinical, and experimental advances and innovations. Literature reviews are also included. Direct all inquiries to David $L$ McGlasson MS, MLS, 59th Clinical Research Division/SGRL, 2200Berquist Dr., Bldg. 4430, Lackland AFB TX 782369908,david.mcglasson@lackland.af.mil

Clinical Laboratory Science encourages readers to respond with thoughts, questions, or comments regarding these articles. Email responses to westminsterpublishers@comcast.net. In the subject line, please type the journal issue and lead author such as "CLIN LAB SCI 24(3) RE PRICE". Selected responses may appear in the Dialogue and Discussion section in a future issue. Responses may be edited for length and clarity. We look forward to hearing from you. 